\title{
Experimental installation of wireless power transfer system based on the series resonance technology
}

\author{
Sarab Al-Chlaihawi ${ }^{1}$, Adnan Hasan Tawafan ${ }^{2}$, Fatima Kadhem Abd ${ }^{3}$ \\ ${ }^{1}$ Najaf Technical Institute, Al-Furat Al-Awsat Technical University, Al-Najaf, Iraq \\ ${ }^{2,3}$ Karbala Technical Institute, Al-Furat Al-Awsat Technical University, Al-Najaf, Iraq
}

\begin{tabular}{l} 
Article Info \\
\hline Article history: \\
Received Apr 21, 2020 \\
Revised May 10, 2020 \\
Accepted Jun 17, 2020 \\
\hline
\end{tabular}

Keywords:

Battery charging

Inductive power transfer

Inductively coupled coils

Resonant

Zero-voltage switching

\begin{abstract}
In this work, we aim to install a wireless power transfer (WPT) system experimentally. Series resonance technology was used to achieve zerovoltage switching (ZVS). We investigated the impact of the primary and secondary resonance frequencies $\left(f_{p}\right.$ and $\left.f_{d}\right)$, and inverter frequency switching (fch) on the efficiency $(\beta)$ and maximum transfer power in a WPT system based on the inductive wireless power transfer (IWPT) technology. An ultrasonic device was utilized as a generator to excite the coil at the primary side. The experimental outcomes showed that there is an optimum unlike $f_{p}$ and $f_{d}$ can be got to match fch. It was found also that there is a trade-off between the power supplied to the load (PRL) and DC-DC efficiency ( $\beta$ ). At an air-gap of $5 \mathrm{~cm}$, the obtained results are recorded as follows; the peak recorded system $\beta$ is $62 \%$ that was obtained at $f_{p}=19 \mathrm{kHz}, f_{d}=f_{c h}=24 \mathrm{kHz}$ that is corresponding to $101.88 \mathrm{~W}$ of PRL; whereas the highest PRL resulted i.e. $244 \mathrm{~W}$ when $\mathrm{f}_{\mathrm{p}}=19 \mathrm{kHz}, \mathrm{f}_{\mathrm{d}}=24 \mathrm{kHz}, \mathrm{f}_{\mathrm{ch}}=21 \mathrm{kHz}$ at $61 \%$ of $\beta$; in such case, the maximum $\beta^{*}$ PRL multiplication was achieved i.e. 149. Moreover, the coils' misalignment was studied. The outcomes showed that the lateral misalignment has worst effect on the PRL and $\beta$ than the air-gap. The experimental results were validated with simulation ones.
\end{abstract}

This is an open access article under the CC BY-SA license.

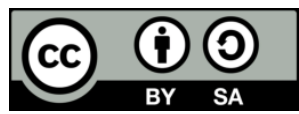

\section{Corresponding Author:}

Sarab Al-Chlaihawi,

Najaf Technical Institute,

Al-Furat Al-Awsat Technical University,

Email: inj.srb@atu.edu.iq

\section{INTRODUCTION}

The interest in the wireless power transfer (WPT) technique has considerably increased in recent few years, because of the safety and conveniences over the wired charging technology. In general, the WPT technology for electric vehicles (EVs) and smartphones battery charging includes inductive and capacitive wireless power transfer (IWPT and CWPT) [1-5].

In this work, only the IWPT technique is presented, where the power transmits from the primary coil to the secondary one electromagneticaly. The coupling interface surface area between the coils and air-gap are parameters impacting the coupling factor $(\mathrm{k})$. This parameter has an effect on the whole system's efficiency and performance. The air-gap between the coils is the most challenging factor. As the air-gap rises, the magnetizing current, leakage inductance, and input VA rating rise accordingly. Consequently, the system cost increases, system efficiency diminishes due to losses increasing [6-8].

A resonance circuit technique has been utilized to enhance the IWPT system efficiency and performance $[2,9]$. The resonance circuit is nothing but capacitor(s) linked with the coils in series/parallel to compensate its inductance. At the primary side, the resonance circuit minimizes reactive power, improves the 
power factor, less VA ratings which result in less voltage stress on the system's components of the system, and low inverter cost. At the secondary side, the resonance circuit improves the system efficiency and maximizes the power delivered to the battery. For the EVs applications, the normally utilized inverter switching frequency within the range of $10-200 \mathrm{kHz}$. The switching frequency is mainly based on the air-gap and coils' size. The high-quality factor of the coils results in high power transmission efficiency $[6,10,11]$.

However, to make the most of resonance technology, the resonance frequency at the primary $\left(f_{p}\right)$ should be correlated with the resonance frequency at the secondary $\left(f_{d}\right)$ side; and both $f_{p}$ and $f_{d}$ should be correlated with the inverter switching frequency $\left(f_{c h}\right)$ to achieve zero-voltage switching (ZVS). Recently, in $[2,12,13]$, in a bid to achieve the highest power transfer level, the $f_{p}$ and $f_{d}$ were set to be equal to the fch. While in [14], it was found that at fch equal to the fd, the maximum power transfer efficiency was achieved [14]. It was proven that the transmitted power is not constantly an optimum at resonance case [15]. The power transfer level is mainly based on the coupled coils' inductance and its quality factor, switching frequency, the square of input current and mutual inductance. However, there is no interest has given to discover an optimum $f_{c h}, f_{p}$, and $f_{d}$ to accomplish the highest power transfer level and efficiency $[16,17]$. In this work, the impact of various $f_{c h}, f_{p}$, and $f_{d}$ on the IWPT level and efficiency was studied; to get resonance circuits, resonance capacitors were utilised to adjust $f_{p}$ and $f_{d}$. This aims to accomplish a maximum WPT efficiency and load power by discovering an optimum $f_{c h}, f_{p}$, and $f_{d}$. Moreover, since the the coupled coils misalignment is a common problem in the IWPT systems, we carried out a study to impact of this issue on the DC-DC system efficiency ( $\beta$ ) and resistive load power (PL).

The transferred power and efficiency in a WPT system basically rely on the resonance frequency $[18,19]$, magnetic coupling factor, $\mathrm{k}$, and mutual inductance, $\mathrm{M}$, which are mainly based on the coil configurations and varied with the air-gap (d) and coils' misalignment [18-20]. In this work, the spiral coil configuration of copper wires was built experimentally to deliver power wirelessly to a resistive load through an air-gap of $5 \mathrm{~cm}$. The misalignment issue was investigated as well.

The next sections of the paper are arranged as follows: Section 2 presents the WPT system, which includes the experimental setup, mathematical model as well as the considered coil configuration and misalignment between the inductively coupled coils. Section 3 explains the methodology used to implement the experimental work and how the data are collected. Section 4 illustrates the experimental outcomes and discussion. Section 5 presents the conclusion.

\section{INDUCTIVE WIRELESS POWER TRANSFER SYSTEM}

As mentioned earlier, the d between the coupled coils is playing a major role in any IWPT system performance. The self-inductances of the primary and secondary (L1 and L2) coils, k and M are parameters utilized to describe the inductive coupler; The relation between these parameters is expressed in (1) [20].

$$
M=k \sqrt{\mathrm{L}_{1} \mathrm{~L}_{2}}
$$

\subsection{Experimental Setup}

The adapted IWPT system includes an ultrasonic generator (see technical characteristics in Table) that was utilized to excite the primary coil; based on it favorable features among other topologies, the seriesseries (SS) resonance technology was utilized [2]. The experimental setup of the presented IWPT system is depicted in Figure 1. Where $\mathrm{C}_{\mathrm{p} 1}, \mathrm{C}_{\mathrm{p} 2}, \mathrm{R}_{1}$, and $\mathrm{R}_{2}$, are the equivalent parallel capacitances and the equivalent series resistances, respectively. From Figure 1, it can be noted that the ultrasonic generator includes the followings components:

- Generator unit,

- Remotely controlled panel which used for parameterization,

- Adapter which is used for external control;

- A half-bridge inverter which is made from IGBT transistors

The $\mathrm{f}_{\mathrm{ch}}$ is controlleded by utilizing the handheld control unit which linked through RS485-232 adapter to the generator unit. The ultrasonic generator's technical characteristics are mentioned in Table 1 [21]. However, due to its most robust to the rotation misalignment and uniform flex distribution, the spiral configuration was adapted to create the coils:

- The copper wire coils;

- Capacitors (WIMA type) were utilized for the SS resonance technology, the $f_{p}$ and $f_{d}$ are calculated theoretically as in equation (2).

- A full-bridge rectifier made of four power diodes of type Schottky (DSS 2x61-01 A). To soak up the generated heat and wasted it. The rectifier mounted over the heatsink with dimension $20 \times 12.5 \times 2.5 \mathrm{~cm}$. 
- A filter capacitor $(2200 \mu \mathrm{F})$ linked parallelly to load (i.e. resistive) to supply it with a pure DC power.

$$
f_{p}=\frac{1}{2 \pi \sqrt{L_{1} C_{1}}}, f_{d}=\frac{1}{2 \pi \sqrt{L_{2} C_{2}}}
$$

Table 1. The ultrasonic generator's characteristics for the MSG.1200.IX.LF model [21].

\begin{tabular}{cc}
\hline Device elements & Specifications \\
\hline Weight & $10 \mathrm{~kg}$ \\
Dimensions (h x w x d) & $250 \mathrm{~mm} \times 150 \mathrm{~mm} \times 450 \mathrm{~mm}$ \\
Supply Voltage and frequency & $230 / 220 \mathrm{~V}(50 \mathrm{~Hz})$ \\
Input Power (Max) & $700 \mathrm{~W}$ \\
Output HF Voltage & $500 \mathrm{~V}-\mathrm{rms}$ \\
Average Output Power (continuous) & $600 \mathrm{~W}$ \\
Max. pulsed power (Peak Output) & $3000 \mathrm{~W}$ \\
Inverter frequency & $17.5-28 \mathrm{kHz}$
\end{tabular}

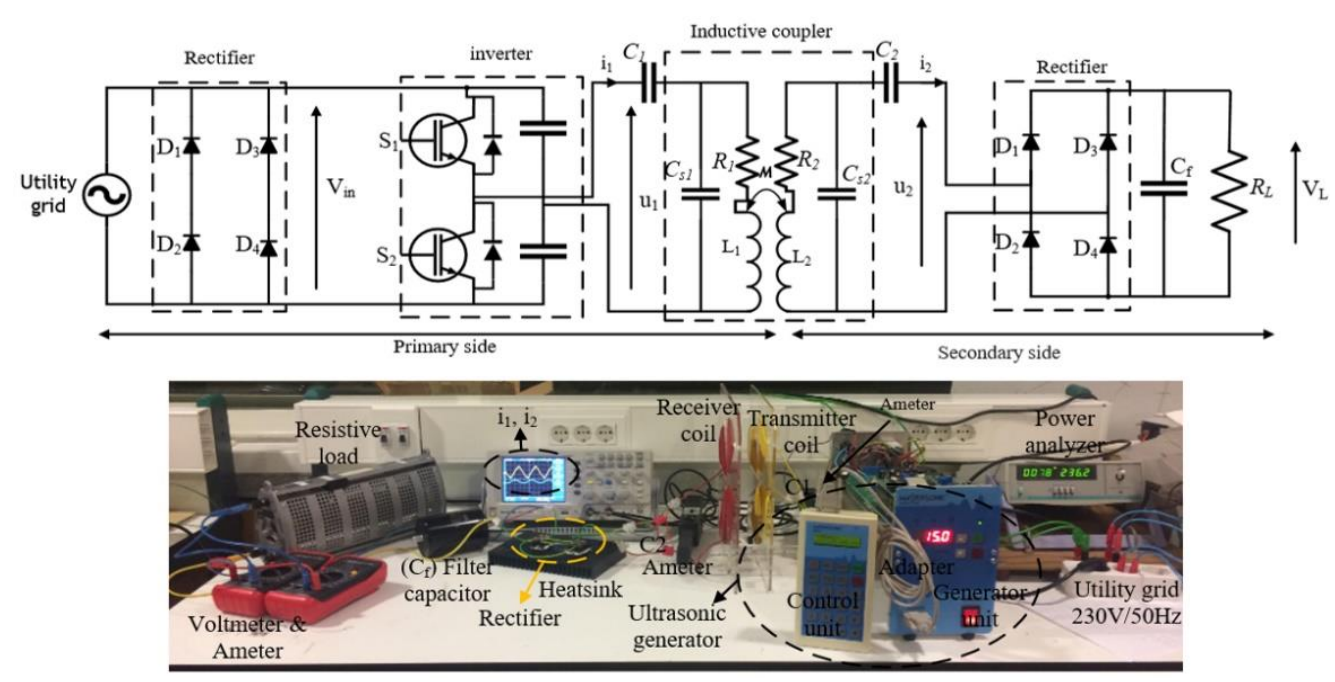

Figure 1. Experimental setup of IWPT system

\subsection{Mathematical model}

To validate the empirical outcomes with the theoretical ones, the mathematical IWPT system model is presented here. The dependent voltage source was used to model the inductive coupler, the equivalent circuit of the IWPT system that mentions in section 2.1 is shown in Figure 2, where the output of the ultrasonic generator is modeled as a square voltage source with an RMS value of $\left(\mathrm{u}_{1}\right)$.

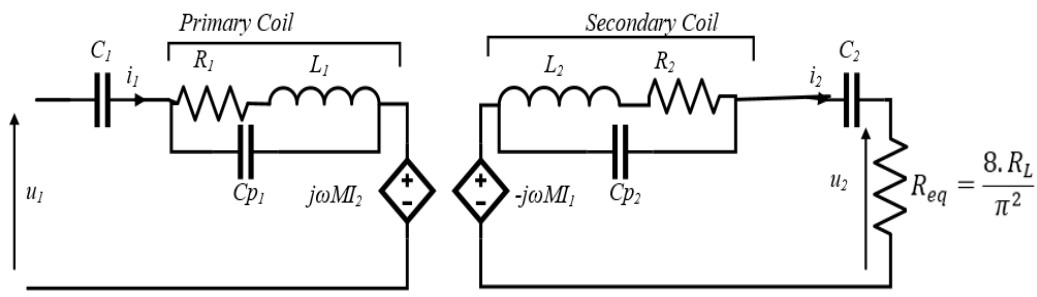

Figure 1. The equipollent model based on the adapted IWPT system

The equivalent primary impedance $\left(Z_{p}\right)$, secondary impedance $\left(Z_{s}\right)$, reflected impedance from secondary to the primary $\left(Z_{r}\right)$, and input impedance $\left(Z_{\text {in }}\right)$ are expressed in equations (3), (4), (5), and (6), respectively; the effect of the $\mathrm{Cp} 1$ and $\mathrm{C}_{\mathrm{p} 2}$ are neglected due to their small values compare with other parameters values.

Experimental installation of wireless power transfer system based on the series-... (Sarab Al-Chlaihawi) 


$$
\begin{aligned}
& Z_{p}=R_{1}+j \omega_{c h} L_{1}+\frac{1}{j \omega_{c h}\left(C_{1}\right)} \\
& Z_{s}=R_{2}+j \omega_{c h} L_{2}+\frac{1}{j \omega_{s}\left(C_{2}\right)} \\
& Z_{r}=\frac{M^{2} \omega_{c h}^{2}}{Z_{2}} \\
& Z_{\text {in }}=Z_{p}+Z_{r}=Z_{p}+\frac{\omega_{c h}^{2} M^{2}}{Z_{s}}
\end{aligned}
$$

Based on Figure 2, the expression of the RMS input current at the primary circuit $i_{1}$ and RMS secondary current $i_{2}$ are described in equations (7) and (8), respectively.

$$
\begin{aligned}
& i_{1}=\frac{u_{1}}{\left|z_{i n}\right|} \\
& i_{2}=\frac{\left|-j \omega M u_{1}\right|}{\left|z_{p} Z_{s}+\omega_{c h}^{2} M^{2}\right|}
\end{aligned}
$$

From equations (7) and (8), the voltage gain $\left(\mathrm{G}_{\mathrm{v}}\right)$ can be written as;

$$
\left|G_{v}\right|=\frac{u_{2}}{u_{1}}=\frac{i_{2} R_{e q}}{i_{1} Z_{i n}}=\frac{\left|-j \omega_{c h} M R_{e q}\right|}{\left|Z_{p} Z_{s}+\omega_{c h}^{2} M^{2}\right|}
$$

However, the DC load power $\left(\mathrm{P}_{\mathrm{RL}}\right)$ which delivered to load is described as follows;

$$
P_{L}=\frac{u_{2}^{2}}{R_{e q}}=i_{2}^{2} \cdot R_{e q}
$$

\subsection{Inductively coupled coils}

Generally, the $\mathrm{k}$ is utilized to predict the IWPT performance $[2,10,11]$; The DC-DC efficiency can be computed as follows;

$$
\beta=\frac{P_{L}}{P_{\text {in }}}
$$

where the input DC power (Pin) was calculated using approximation formula:

$$
P_{\text {in }}=\text { the input power }(\mathrm{AC})-\text { no-load losses (i.e. ultrasonic generator) }
$$

In this work, the well-aligned coils, as shown in Figure 3(a), air-gap fluctuation as well as the lateral misalignment, Figure 3(b), with $\mathrm{L}>0$ between the coils were investigated.

Based on the equation (13), the k was measured experimentally as follows,

- A function generator with a set voltage of $\mathrm{V}_{1}$ was utilized to energize the primary coil;

- Utilizing an oscilloscope, the induced $\operatorname{EMF}\left(\mathrm{V}_{2}\right)$ was measured at the secondary coil.

$$
k=\frac{V_{2}}{V_{1}}
$$

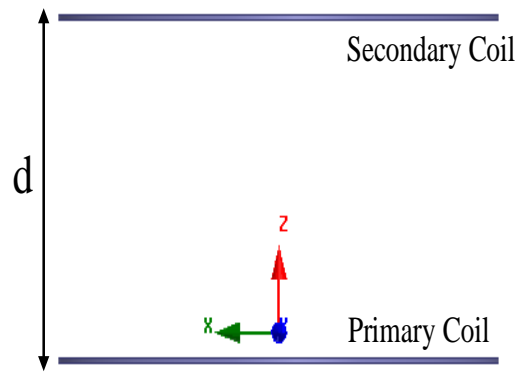

(a)

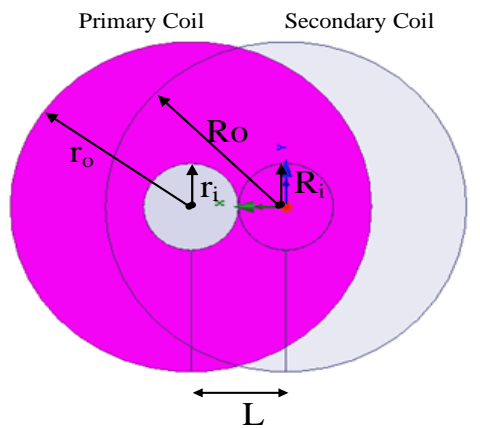

(b)

Figure 3. Inductively Coupled Coils, (a) well-alignment coils (b) coupled coils with lateral misalignment (L) 


\section{MATERIALS AND METHODS}

In this paper, an IWPT system was implemented experimentally. This work involves the study of the impact of the $f_{c h}, f_{p}$, and $f_{d}$ on the $P_{R L} \& \beta$ and investigate the optimum $\beta{ }^{*} P_{R L}$ condition. The $f_{c h}$ is controlled using the ultrasonic generator's control unit. The $f_{p}$ and $f_{d}$ were controlled utilizing the resonance capacitors that are connected in parallel and/or series to obtain the desired resonant frequency. Based on the frequency characteristics, the $f_{p}$ and $f_{d}$ were computed utilizing the LCR HiTESTER of model HIOKI 3532-50.

The power analyzer connects the ultrasonic device to the $230 \mathrm{~V} / 50 \mathrm{~Hz}$ of electricity plug. The function of the power analyzer is to compute the AC input electric power. The ultrasonic device's no-load losses were gauged; these losses were assumed to be the same at all loading conditions; this presumption was utilized to compute the input DC power (equation (12)).

A spiral shape was considered to constitute the coils:

- The length each copper coil wire is $17 \mathrm{~m}$,

- The cross-section area of the copper wire is $1.5 \mathrm{~mm}^{2}$,

- $\mathrm{r}_{\mathrm{i}}=\mathrm{R}_{\mathrm{i}}=2.5 \mathrm{~cm}, \mathrm{r}_{\mathrm{o}}=\mathrm{R}_{\mathrm{o}}=11.88 \mathrm{~cm}$ with $2 \mathrm{~mm}$ of coil pitch, and

- The turns number of the coils is the same i.e. 34 .

Utilizing digital RLC meter, the coils' parameters were determined.

Several experiments were carried out at well-alignment coils at $d=5 \mathrm{~cm}$ with various $\mathrm{f}_{\mathrm{p}}, \mathrm{f}_{\mathrm{d}}$, and $\mathrm{fch}_{\mathrm{ch}}$; the $\beta$ was identified accordingly at each situation. Moreover, the impact of the $d$ and $L$ on the PRL was researched. It was presented a case to research the effect of $f_{\text {ch }}$ on PRL. The imperical data were validated with the theoretical omes that was obtained based on the mathematical model implemented in MATLAB.

\section{EXPERIMENTAL OUTCOMES AND DISCUSSION}

This section shows the experimental outcomes which include the parameters of the coils and adjusting $f_{c h}, f_{p}$, and $f_{d}$ to achieve an optimum $\beta$ and $P_{R L}$. Based on the ultrasonic generator's technical characteristics (Table), only $15 \%$ of the device power was utilized with no-load losses $18 \mathrm{~W}$.

\subsection{Coils parameters}

The coils' resistance, inductance, and quality factor were determined experimentally by utilizing the digital RLC meter as shown in Table 2. The $f_{p}$ and $f_{d}$ were calculated utilizing the frequency characteristics in order to take into account the coils' distributed capacitances. The obtained outcomes showed that

- When the coil connected in series with a capacitor of $0.47 \mu \mathrm{F}, \mathrm{f}_{\mathrm{p}}$ and $\mathrm{f}_{\mathrm{d}}$ are about $19 \mathrm{kHz}$.

- Two parallel capacitors of $0.15 \mu \mathrm{F}$ are linked in series with a coil, that gives a $f_{p}$ and $f_{d}$ are about $24 \mathrm{kHz}$.

- Three parallel capacitors of $0.15 \mu \mathrm{F}$ are linked in series with a coil, that gives an $f_{p}$ and $f_{d}$ about $28 \mathrm{kHz}$.

Table 1. Experimental measured parameters of the coupled coils at $1 \mathrm{kHz}$.

\begin{tabular}{ccc}
\hline Parameter & Primary coil & Secondary coil \\
\hline $\mathrm{L}_{1,2}(\mu \mathrm{H})$ & 148.2 & 151 \\
$\mathrm{R}_{1,2}(\Omega)$ & 0.446 & 0.474 \\
$\mathrm{Q}_{1,2}$ & 2.13 & 2.02 \\
$\mathrm{k} \quad \quad$ at $=5 \mathrm{~cm}$ & \multicolumn{2}{c}{0.42} \\
$\mathrm{M}(\mu \mathrm{H}) \quad$ a $\mathrm{c}=52.82$ \\
\hline
\end{tabular}

\subsection{Resonance}

As mentioned in section 4.1, the $f_{p}$ and $f_{d}$ were regulated utilizing resonance capacitors. The of $L_{1}$ and $L_{2}$ at $1 \mathrm{kHz}$ were assumed to have constant values at higher frequencies when the $f_{p}$ and $f_{d}$ computed. Therefore, for various $f_{c h}$, at $R_{L}=32 \Omega, d=5 \mathrm{~cm}$, the impact of the $f_{p}$ and $f_{d}$ on the $\beta$ was investigated, the outcomes are shown in Figure 4. As can be observed from Figure 4, the maximum achieved $\beta$ at $f_{\mathrm{ch}}$ of $28 \mathrm{kHz}$ is $62 \%$ (at this efficiency the obtained $\mathrm{P}_{\mathrm{RL}}$ is $101.8 \mathrm{~W}$ ) that was achieved at $\mathrm{f}_{\mathrm{p}}=19 \mathrm{kHz}, \mathrm{f}_{\mathrm{d}}=24 \mathrm{kHz}$. The next highest $\beta$ i.e. $61 \%$ was obtained at $\mathrm{f}_{\mathrm{p}}=19 \mathrm{kHz}, \mathrm{f}_{\mathrm{d}}=24 \mathrm{kHz}$, and $\mathrm{f}_{\mathrm{ch}}=21 \mathrm{kHz}$ (at this efficiency the obtained $\mathrm{P}_{\mathrm{RL}}$ is $244.13 \mathrm{~W}$ ). Based on the obtained results, the maximum $\beta$ values were occurred at $\mathrm{f}_{\mathrm{d}} \approx \mathrm{f}_{\mathrm{ch}}$. At this condition, the power reflected from the secondary side to the primary side removed. The obtained outcomes are correlated with the ones presented in [14]. The maximum achievable $P_{R L}$ is $244.13 \mathrm{~W}$ was obtained at $f_{c h}>$ $\mathrm{f}_{\mathrm{p}}$. At this condition, the ZVS occur since the inverter inductively loaded; this makes the losses of the halfbridge inverter are near to zero [14, 24]. 


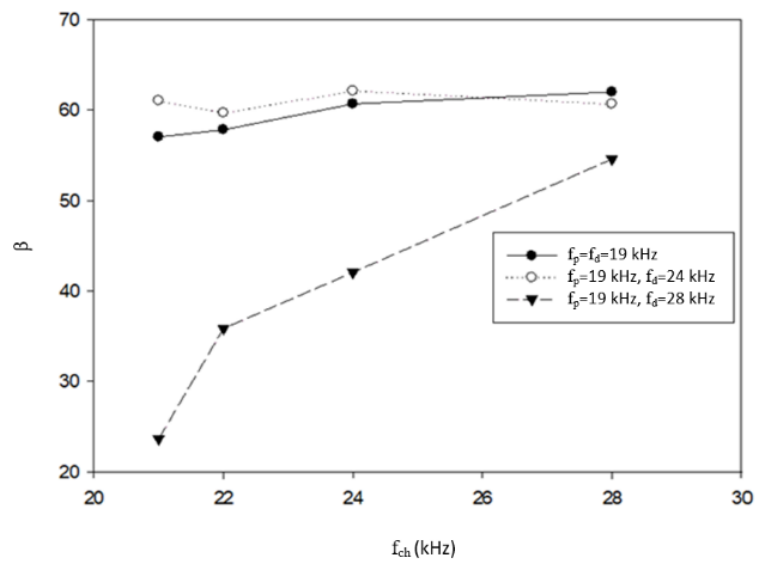

Figure 4. $\beta$ against $f_{\text {ch }}$ for various $f_{p}$ and $f_{d}$

As it is known, high $\beta$ with $\mathrm{P}_{\mathrm{RL}}$ is an eligible outcome. Therefore, the optimum $\beta^{*} \mathrm{P}_{\mathrm{RL}}$ factor was studied. The obtained outcomes as shown in Figure 4 indicate that the peak value i.e $149\left(\mathrm{P}_{\mathrm{RL}} \approx 244 \mathrm{~W} \& \beta \approx\right.$ $61 \%$ ) accomplished at $\mathrm{f}_{\mathrm{p}}=19 \mathrm{kHz}, \mathrm{f}_{\mathrm{d}}=24 \mathrm{kHz}$, and $\mathrm{f}_{\mathrm{ch}}=21 \mathrm{kHz}$ where $\mathrm{f}_{\mathrm{d}} \approx \mathrm{f}_{\mathrm{ch}}$. The slight difference between $f_{c h}$ and $f_{d}$ because the resistive load made of copper wire that has a small inductance which effects the $f_{d}$ value. In other words, according to equation (2), the real $f_{d}$ is a bit below than $24 \mathrm{kHz}$ i.e. $f_{\text {ch }} \approx f_{d}$; where at this condition zero (or very slight amount) reflected power obtained.

The frequency characteristics behavior of $\mathrm{P}_{\mathrm{RL}}$ and $\mathrm{P}_{\text {in }}$ are analogous. Therefore, only the $\mathrm{P}_{\mathrm{RL}}$ is presented here. At $f_{p}=19 \mathrm{kHz}, f_{d}=24 \mathrm{kHz}$ condition (peak $\beta^{*} \mathrm{P}_{\mathrm{RL}}$ ), the impact of the $\mathrm{f}_{\mathrm{ch}}$ on the $\mathrm{P}_{\mathrm{L}}$ was investigated imperically when $\mathrm{d}=5 \mathrm{~cm}, \mathrm{P}_{\mathrm{RL}}=32 \Omega$; the measure $\mathrm{u}_{1}$ experiment values were used in the IWPT system's mathematical model to compute the $\mathrm{P}_{\mathrm{L}}$ for validation purpose, the outcomes are shown in Figure 5.

As can be seen, Figure 5, the $P_{R L}$ declines considerably as the $f_{c h}$ rise; for each situation, the peak $P_{R L}$ was resulted when $f_{p}$ a bit less than $f_{c h}$. The difference between the experimental and simulation curves due to the losses of the ultrasonic generator which is not considered in the mathematical model.

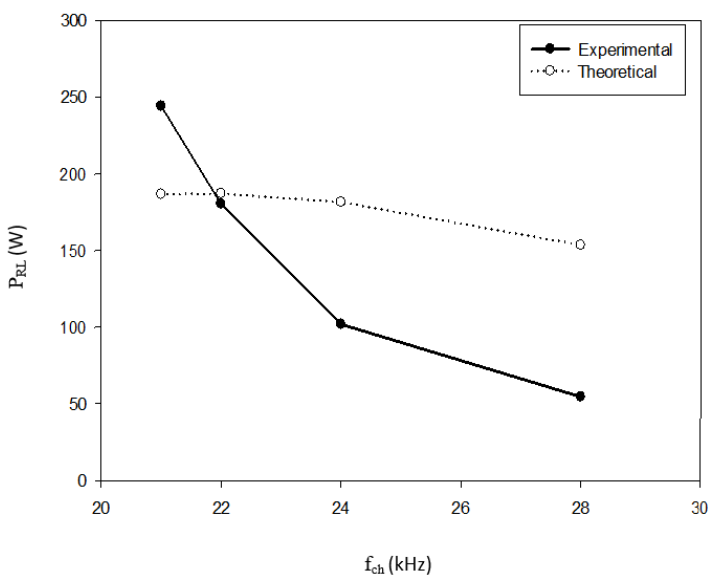

Figure 5. $P_{R L}$ against $f_{c h}$ at $f_{p}=19 \mathrm{kHz}, f_{d}=24 \mathrm{kHz}$

\subsection{Misalignment}

At peak $\beta^{*} P_{R L}$ situation i.e. $f_{p}=19 \mathrm{kHz}, f_{d}=24 \mathrm{kHz}, f_{c h}=21 \mathrm{kHz}$, the air-gap and lateral misalignment variations impact on the $\mathrm{P}_{\mathrm{RL}}$ were researched; the outcomes are illustrated in Figure 6 . As can be noted, Figure 6, the two curves have same behavior; where, as the d rises the PRL sharply get down. Similarly, as the L rises the PRL considerably decreases. However, to supply a fixed power of good quality and high efficiency the misalignment should be avoided. A mechanic or magnetic trap have been used by some IWPT systems to avoid the misalignment [25]. 

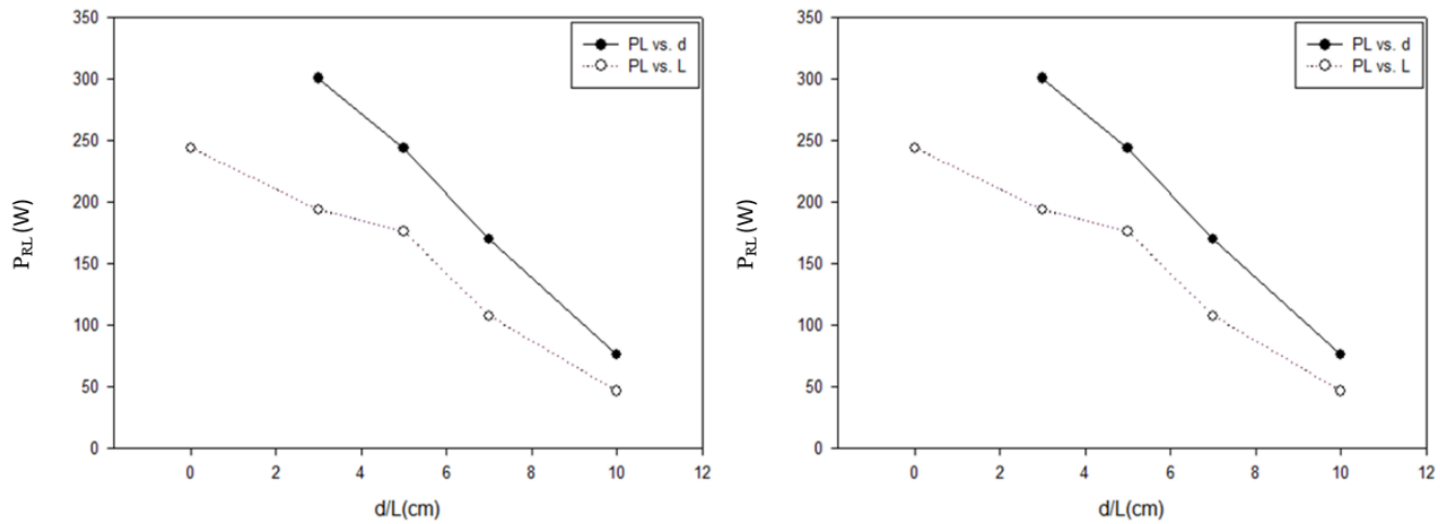

Figure 6. $\mathrm{P}_{\mathrm{RL}}$ versus $\mathrm{d}$ and $\mathrm{L}$ at $\mathrm{d}=5 \mathrm{~cm}$

\section{CONCLUSION}

This work has researched the impact of the $f_{c h}, f_{p}$, and $f_{d}$ in an IWPT system on the $P_{R L}$ and $\beta$. The outcomes proved an optimum $f_{p}, f_{d}$, and $f_{c h}$ values are existe to achieve peak reachable $\beta$. Meanwhile, there are other $f_{p}, f_{d}$, and $f_{c h}$ values to achieve peak reachable $P_{R L}$. The imperical outcomes determined that $f_{c h}$ and $f_{d}$ should have same values (or almost equal) with $f_{c h}>f_{d}$ and both should be a bit more than $f_{p}$ to achieve peak $\beta^{*} \mathrm{P}_{\mathrm{RL}}$. The most we can talk about that these results highlight the enhancements in our work by studying the best $f_{p}$ and $f_{d}$ values to be tuned with the $f_{c h}$ as well as regulate the $f_{p}$ and $f_{d}$ in a bit to improve the $\beta^{*} P_{R L}$ factor. The ultrasonic device with adjustable $f_{c h}$ has utilized in the primary side to supply its coil; while the $f_{p}$ and $\mathrm{f}_{\mathrm{d}}$ have been regulated by utilizing resonance capacitors. However, some ultrasonic generator limitations are worthy of note that the $\mathrm{f}_{\mathrm{ch}}$ cannot exceed the limit $(17.5-28 \mathrm{kHz})$. The coils' misalignment has been researched as well; the outcomes identified that as the $d$ has a more negative impact on $P_{R L}$ than L. However, the future work should include a study of higher frequency ranges, for example, $120 \mathrm{kHz}$.

\section{REFERENCES}

[1] M. Al-Saadi et al., "Capacitive power transfer for wireless batteries charging," EEA - Electroteh. Electron. Autom., vol. 66, no. 4, 2018.

[2] A. Crăciunescu et al., "Analysis and Comparison of Resonance Topologies in 6.6kW Wireless Inductive Charging for Electric Vehicles Batteries,” Procedia Manuf., vol. 32, pp. 426-433, 2019.

[3] M. Al-saadi et al. "A Comparative Study of Capacitive Couplers in Wireless Power Transfer," 2018 International Symposium on Fundamentals of Electrical Engineering (ISFEE), pp. 1-6, 2016.

[4] E. A. Hussien et al., "Comparative Study of Compensation Circuit Topologies in 6 . 6kW Capacitive Power Transfer System," 2019 11th Int. Symp. Adv. Top. Electr. Eng., pp. 1-6, 2019.

[5] S. Al-Chlaihawi et al., "Analysis of Charge Plate Configurations in Unipolar Capacitive Power Transfer System for Charging the Electric Vehicles Batteries," in 12th International Conference on Interdisciplinarity in Engineering, 2018.

[6] S. Al-Chlaihawi et al., "Inductive Power Transfer for Charging the Electric Vehicle Batteries," EEA, no. 4, 2018.

[7] S. Al-Chlaihawi et al., "A New Analytical Formula for Coupling Capacitance of Unipolar Capacitive Coupler in Wireless Power Transfer System," in 2019 11th International Symposium on Advanced Topics in Electrical Engineering (ATEE), 2019, pp. 1-6.

[8] M. F. C. Jorgetto et al., "Wireless inductive power transfer, oriented modeling and design," 2015 IEEE 13th Brazilian Power Electron. Conf. 1st South. Power Electron. Conf. COBEP/SPEC 2016, 2015.

[9] D. Kim et al.," "State-of-the-art literature review of WPT: Current limitations and solutions on IPT," Electr. Power Syst. Res., vol. 154, pp. 493-502, 2018.

[10] M. A. F. Al-Qaisi et al., "High performance DC/DC buck converter using sliding mode controller," International Journal of Power Electronics and Drive System (IJPEDS), vol. 10, no. 4, p. 1806, 2019.

[11] B. Regensburger et al., "High-Performance Large Air-Gap Capacitive Wireless Power Transfer System for Electric Vehicle Charging," 2017 IEEE Transportation Electrification Conference and Expo (ITEC), pp. 638-643, 2017.

[12] P. S. R. Nayak et al., "Performance analysis of series/parallel and dual side LCC compensation topologies of inductive power transfer for EV battery charging system," Front. Energy, 2018.

[13] G. Rituraj et al., "Analysis and comparison of series-series and series-parallel topology of contactless power transfer systems," IEEE Reg. 10 Annu. Int. Conf. Proceedings/TENCON, vol. 2015-Janua, 2015.

[14] H. Li et al.," "Study on efficiency maximization design principles for Wireless Power Transfer system using magnetic resonant coupling," 2013 IEEE ECCE Asia Downunder, pp. 888-892, 2013.

[15] D. M. Vilathgamuwa et al., "Wireless power transfer (WPT) for electric vehicles (EVS)—Present and future 
trends," Plug in electric vehicles in smart grids, pp. 33-61, 2015.

[16] J. T. Gonçalves et al., "Three-Phase Unidirectional Transformerless Hybrid Rectifier with Boost Converter," in 2019 1st Global Power, Energy and Communication Conference (GPECOM), 2019, pp. 158-163.

[17] Z. Pantic et al., "Multifrequency inductive power transfer," IEEE Trans. Power Electron., vol. 29, no. 11, pp. 5995-6005, 2014.

[18] M. AL-SAADI et al., "Maximum Power Point Tracking and Power/Voltage Regulation for Inductive Wireless Battery Charging," in 2019 Electric Vehicles International Conference (EV), 2019.

[19] C. T. Rim et al., "Introduction to Electric Vehicles (EVs)," Wirel. Power Transf. Electr. Veh. Mob. Devices, pp. 43-49, 2017.

[20] M. Al-saadi, et al., "New Analytical Formulas For Self-Inductances Of Inductively New Analytical Formulas For Self-Inductances Of Inductively Coupled Ring Coils In Wireless," Univ. Politeh. Bucharest Sci. Bull., pp. 260-274, 2019.

[21] X. Msg et al., "System Operation Manual Ultrasonic Generator And Power Supply Mmm, Wideband Multifrequency Technology System Operation,” April, pp. 1-70, 2007.

[22] M. Q. Nguyen, et al., "A Mutual Inductance Approach for Optimization of Wireless Energy Transmission," Texas Symposium on Wireless and Microwave Circuits and Systems, pp. 4-7, 2014.

[23] W. Zhang et al., "Analysis and Comparison of Secondary Series- and Parallel-Compensated Inductive Power Transfer Systems Operating for Optimal Efficiency and," Power Electron. IEEE Trans., vol. 29, no. 6, pp. 29792990, 2014.

[24] S. Valtchev et al., "Control for the Contactless Series Resonant Energy Converter," in Emerging Capabilities and Applications of Wireless Power Transfer, IGI Global, 2019, pp. 102-140.

[25] M. Al-Saadi, et al., "Comparison of Spiral and Square Coil Configurations in Wireless Power Transfer System for Contactless Battery Charging," in 2019 Electric Vehicles International Conference (EV), 2019, pp. 1-5.

\section{BIOGRAPHIES OF AUTHORS}

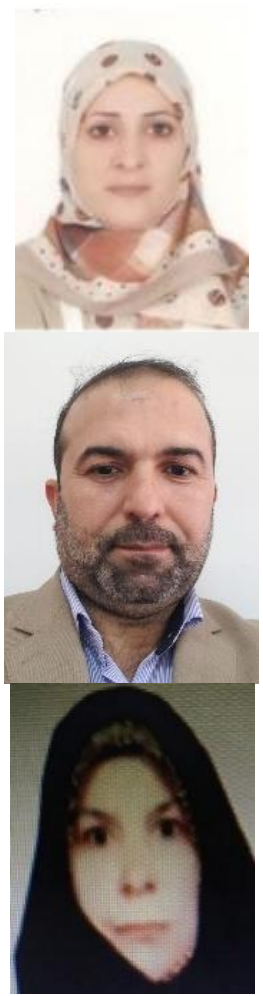

Sarab Al-Chlaihawi was born in Najaf, Iraq, in 1973. She received the B.Sc. degree in electrical engineering/University of Technology (Iraq), in 1995. In 2012, she received the M.Sc. degree in Electrical and Electronic Engineering, Jawaharlal Nehru technological University, Hyderabad, India. She received the Ph.D. degree in electrical engineering/University Politehnica of Bucharest, Romania, in 2018. Her research interests concern: power electronic, electric vehicles, renewable and sustainable energy systems. Email address: inj.srb@atu.edu.iq

Adnan Hasan Tawafan was born in Kerbala, Iraq, in 1971. He received the M.S. degree in electrical engineering from University of Technology, Baghdad, Iraq in 2002, and the Ph.D. degree in electrical engineering from UTeM, Malaysia in 2014. Since 2005, he has been with electrical technical department in Technical Institute of Karbala, Iraq. His research interests concern: analysis and design of distribution system, protection, power quality improvement, power electronics applications and risk management. Email address: inkr.adn@atu.edu.iq

Fatima Kadhem Abd was born in Kerbala, Iraq, in 1968. She received the B. degree in electrical engineering from University of technology, Baghdad, Iraq in 1990, Since 2000, she has been with electrical technical department in Technical Institute of Karbala, Iraq. Her research interests concern: analysis of distribution system. Email address: fatima@kit.edu.iq 